\title{
Research on Investment Efficiency Evaluation of Urban Agglomeration Environmental Pollution Control- evidence from the Yangtze River Delta Urban Agglomeration
}

\author{
Hairong Wang*, Qingyu Li, Xinyu Chen \\ School of Economics and Management, Nanjing Institute of technology. China \\ *Corresponding author. Email: wanghr@nuaa.edu.cn

\begin{abstract}
To control the effects of exogenous environmental variables and random shocks, we construct a six-stage SUPER-SBM DEA model to analyse the investment efficiency of environmental pollution in the Yangtze River Delta in China from 2008 to 2017. The results show that under the condition of maintaining the same output, the pure management efficiency of environmental pollution control investment of China's Yangtze River Delta urban agglomeration in 2008-2017 has about $46 \%$ of input waste. Urban per capita GDP and the government levy on sewage charges effect efficiency improvement positively, while the secondary industry scale, FDI and urbanization level effect the improvement of governance efficiency negatively.
\end{abstract}

Keywords: Environmental pollution control, Urban agglomeration, Investment efficiency, Six-stage SUPER-SBM DEA

\section{INTRODUCTION}

Since mankind entered the era of industrial civilization, Environmental pollution is becoming more and more serious with the rapid economic growth. The traditional "three highs" model which heavily relies on resources and energy inputs to achieve short-term growth has inevitably caused deteriorating air quality, water pollution, land desertification and salinization, and sharp decline in biodiversity. It poses a great threat to the survival of flora and fauna. Therefore, environmental protection is facing tremendous pressures

Along with the urbanization process and the rapid expansion of large and medium-sized cities' scale, the urbanization construction has achieved rapid development. The industrial industry is increasingly showing the pattern of urban cluster development. There are world-class city clusters such as the Atlantic city agglomeration in northeast United States, the great lakes urban agglomeration in North America, the Pacific coast urban agglomeration in Japan, the urban agglomeration of London and Liverpool in Britain, the northwest European urban agglomeration and the Yangtze river delta urban agglomeration in China.
Taking the Yangtze River Delta urban agglomeration as an example, it concentrates a quarter of China' $\mathrm{s}$ economic aggregate and more than a quarter of industrial added value, which is regarded as an important engine of China's economic development, and is the most developed region of China's economy. However, under limited resources, a large number of industrial industries and populations are clustered in these urban agglomerations. The concentration of factories and populations has put tremendous pressure on environmental protection and pollution control of urban agglomerations, causing regional and basin pollution problems in the surrounding environment. According to the "2017 China Ecological Environment Bulletin” , the average daily air compliance time in the Yangtze River Delta region is $74.8 \%$, and the proportion of severe weather and above pollution days is $5.4 \%$. The regional urban air quality is not optimistic. In addition, the pollution in regional water area represented by Taihu Lake still exists. The water quality of the Class III accounts for $11.8 \%$, the Class IV accounts for $52.9 \%$, and the Class V accounts for $35.3 \%$. Water disputes caused by pollution problems in various watersheds also occurred. In order to achieve a sustainable economic development strategy, the total investment of the Chinese 
government in environmental pollution control has maintained a volatile upward trend. The average compound growth rate from 2006 to 2018 reached $15.04 \%$. In 2018, China's investment in environmental pollution control reached a high of 1,322 billion yuan. Furthermore, the investment in environmental pollution control of urban agglomerations is increasing year by year. However, in contrast of the constant effort that had been put into improving environmental problems, current pollution status is disappointing. Therefore, the capital investment of urban agglomerations and the efficiency and effectiveness of environmental pollution control have become hot issues of concern.

\section{REVIEW OF LITERATURE}

At present, the research methods for the evaluation of investment efficiency of environmental pollution control mainly include uniform pollution method, input-output mathematical induction method and DEA method. Freeman and Haveman $(1973)^{[1]}$ first proposed the uniform pollution method. He believed that environmental capacity is a resource. Under-utilization, non-utilization and over-utilization of environmental capacity all have adverse effects on environmental capacity, resulting in inefficient resource allocation. Only when the cost of marginal management and the marginal damage cost of environmental pollution are equal, the utilization level of environmental capacity is the most efficient. At this time, the scale of environmental protection investment is optimal. Cole, Elliott and Shimamoto $(2005)^{[2]}$, Watanabe and Tanaka $(2007)^{[3]}$ proposed a directional distance function method from the perspective of output, and used this method to measure the environmental efficiency of pollutant emissions of 92 power plants, and solved the evaluation issue of unexpected output efficiency. Since the method of single factor correlation analysis can not fully reflect the efficiency of environmental pollution control, the use of DEA method to study environmental pollution control issues of multi-input and multi-output is gradually emerging. Based on the DEA method, Larsson and Telle(2008) $)^{[4]}$ analysed the efficiency of governance pollution of Norwegian companies. Chen, Chang and Chen $(2010)^{[5]}$ measured the pollution control efficiency of waste incinerators in Taiwan through the DEA method. Hua, Bian and Liang(2007) $)^{[6]}$ used DEA model and directed distance function to analyse the relationship between beneficial output and harmful output in environmental benefits, and analysed the impact of carbon dioxide emissions in industrial pollution on environmental benefits. Mandal and Madheswaran(2010 ${ }^{[7]}$,Suzuki, Nijkamp and Rietveld $(2015)^{[8]}$ combined the bad output and super efficiency to improve the DEA model and applied it to the environmental efficiency measurement of the Indian cement industry and Japan's energy environmental efficiency analysis. Yang and $\mathrm{Lu}(2012)^{[9]}$ used three- stage DEA method and spatial geographic variables to analyse the efficiency and differences of environmental pollution control investment in China's eastern, central and western regions. Guo, Tong and Zhang $(2018)^{[10]}$ used the Super-SBM model to evaluate the environmental governance investment efficiency, water pollution control investment efficiency and air pollution control investment efficiency in China's provinces from 2011 to 2014. Sun, Wang and $\operatorname{Li}(2018)^{[11]}$ posed the improved DEA models for measuring emission-reduction and energy-conservation (EREC) efficiency, which considered not only the heterogeneity of energy management in varied regions, but also the technology gap between regions. Li, Ren and Tao $(2019)^{[12]}$ sed the provincial panel data from 2006 to 2015 based on the SBM-DEA model with undesired output, and calculated out the environmental governance investment efficiency of 28 provinces in China. Mardani, Zavadskas and Streimikiene (2016) $)^{[13]}$ eviewed and summarized 144 academic papers published in the journals with large impact factors from 2006 to 2015, and found that the DEA model method is the most widely used in energy efficiency evaluation.

DEA was developed by the operational research expert Charnes, Coopers and Rhodes(1978) ${ }^{[14]}$ which was based on the concept of relative efficiency. Based on the input and output indicators of the decision making unit, it can be judged whether the decision unit is valid for DEA, and whether the decision making unit (DMU) is located in the "production frontier" of the production possibility set. To control the effects of environmental variables and random errors on the effectiveness of DMU, Banker and $\operatorname{Morey}(1986)^{[15]}$ proposed a one-stage DEA model for dealing with exogenous environmental variables, the drawback of which is to assume the direction of the influence of exogenous environmental variables on efficiency. Coelli(1998) $)^{[16]}$ roposed a two-stage DEA model to measure the degree of influence of environmental variables on the efficiency of decision-making units, but the environmental factors and error factors are collectively referred to as external factors, and the effect of random errors on efficiency cannot be eliminated. In order to make full use of the slack variables to remove the influence of environmental factors and random errors on inputs or outputs, and to re-adjust the input or output, Fried, Schmidt and Yaisawarng (1999) ${ }^{[17]}$ roposed the three-stage DEA model, then the four stages DEA model was proposed by Fried, Lovell and $\operatorname{Schmidt}(2002){ }^{[18]}$ ut the truncation problem of the input slack variables was not considered in the three-stage DEA model, resulting in inconsistent parameter estimation. The four-stage DEA model guarantees the consistency of the parameter estimation, but still cannot adjust the influence of the random error. Wang and Geng(2017 ${ }^{[19]}$ roposed the sixstage DEA model based on the development of the fourstage DEA model, which can effectively eliminate the 
influence of environmental variables, random errors and management inefficiency on system efficiency evaluation, and obtain pure management efficiency. But the basic DEA model used by it is a traditional DEACCR model, and the effects of slack variables are not fully considered, the effective units of decision also cannot be further sorted. Learn from Sun, Yuan and Yang $(2017)^{[20]}$ who proposed a non-radial DEA preference model, based on the assumption of variable returns to scale (VRS) and the Directional Distance Function (DDF),Wang ,Hang and $\mathrm{Hu}(2018)^{[21]}$ ho proposed an alternative metafrontier framework and Sun, $\mathrm{Li}$ and Wang $(2019)^{[22]}$ ho proposed a game meta-frontier DEA approach for overcome the shortcomings of the traditional metafrontier framework, this paper combines the idea of six-stage DEA model with the SUPER-SBM DEA model of Tone (2002) $)^{[23]}$ to construct the six-stage SUPER-SBM DEA model to empirically evaluate the investment efficiency of environmental pollution control in the Yangtze River Delta urban agglomeration. On the one hand, it can overcome the shortcomings of the existing DEA model, effectively eliminate the influence of environmental variables, random errors and management inefficiency on investment efficiency evaluation, so as to fully consider the influence of slack variables and further sort the effective units of decision. On the other hand, it also compensates for the existing investment efficiency research on environmental pollution control, which mainly focuses on the national administrative regional level and lacks evaluation on the urban cluster level, so that the proposed efficiency improvement measures are based on a more scientific basis.

\section{MATERIAL AND METHODS}

\subsection{Preliminary determination of the input- output indicator system}

By using the basic principles of determining the input-output indicator system and combining with the characteristics of the DMU efficiency measure, the evaluation index system $\mathrm{Ij}$ is initially determined by a combination of quantitative and qualitative analysis, where $\mathrm{j}=1,2, \ldots, \mathrm{n}$. Assuming that each DMU has $\mathrm{m}$ inputs and s outputs, the input-output vector for the observation value of the $\mathrm{j}$-th decision-making unit DMUj is (Xij, Yrj).

\subsection{The initial efficiency value calculated by using Super-SBM DEA}

In view of the fact that the influence of slack variables and the constraint that the efficiency scores in the model are less than or equal to 1 are not considered in the basic DEA models such as traditional CCR and BCC, Tone $(2001)^{[24]}$ constructed the SBM model that introduced slack variables into the objective function to solve the problem of input-output relaxation. To further solve the sorting problem of relatively efficient units, Tone (2002) constructed the SUPER-SBM model. The initial efficiency value of the index system $\mathrm{Ij}$ and the input redundant slack variables and the output insufficient slack variables are calculated according to the SBM model and SUPER-SBM model .

Table 1. Evaluation index of investment efficiency of urban agglomeration environmental pollution control

\begin{tabular}{|c|c|c|c|c|c|}
\hline Number & Input indicator & Unit & Number & Output indicator & Unit \\
\hline 11 & $\begin{array}{l}\text { Total investment in environmental } \\
\text { governance }\end{array}$ & $\begin{array}{c}\text { Ten } \\
\text { thousand yuan }\end{array}$ & $\mathrm{O} 1$ & $\begin{array}{l}\text { Industrial sulfur dioxide } \\
\text { removal }\end{array}$ & Ton \\
\hline 12 & $\begin{array}{l}\text { Current operating cost of } \\
\text { wastewater/gas treatment }\end{array}$ & $\begin{array}{c}\text { Ten } \\
\text { thousand yuan }\end{array}$ & $\mathrm{O} 2$ & Industrial soot removal & Ton \\
\hline \multirow[t]{3}{*}{13} & $\begin{array}{l}\text { Number of wastewater/gas } \\
\text { treatment facilities }\end{array}$ & Set & $\mathrm{O} 3$ & Industrial dust removal & Ton \\
\hline & & & $\mathrm{O} 4$ & $\begin{array}{l}\text { Harmless treatment rate of } \\
\text { domestic garbage }\end{array}$ & $\%$ \\
\hline & & & O5 & $\begin{array}{l}\text { Domestic sewage treatment } \\
\text { rate }\end{array}$ & $\%$ \\
\hline
\end{tabular}

In view of the public goods characteristics of the environment, government should assume more responsibility for environmental governance. So the environmental pollution control investment in this paper is the input invested by government to reduce the pollution that has formed and prevent possible pollution, including manpower, material resources and financial resources. However, due to the difficulty in obtaining the data on the number of environmental protection professionals in each city, the total investment in environmental governance(I1), current operating cost of waste water/gas treatment(I2), and the number of wastewater/gas treatment facilities(I3) are used to measure the government's physical and financial 
investment in environmental pollution control. At the same time, taking into account the characteristics of urban development, the output of environmental pollution control is mainly based on the treatment volume and treatment rate of urban industrial pollution and domestic pollution. Therefore, Industrial sulfur dioxide removal(O1), industrial soot $\operatorname{removal}(\mathrm{O} 2)$ and Industrial dust removal(O3)are used to measure the output of urban industrial pollution control. The harmless treatment rate of domestic garbage $(\mathrm{O} 4)$ and domestic sewage treatment rate(O5) are used to measure the output of domestic pollution treatment.

\subsection{Data source and processing}

Table 2. Descriptive statistics for all input and output indicators

\begin{tabular}{c|l|l|c|c|c|c}
\hline Variable & Unit & Obs & Max & Min & Mean & Std. Dev. \\
\hline I1 & Ten thousand yuan & 260 & 9235300.20 & 1416.2 & 1918214.76 & 462604.72 \\
\hline I2 & Ten thousand yuan & 260 & 1018214.00 & 3257.1 & 326238.42 & 218148.35 \\
\hline I3 & Set & 260 & 20390 & 144 & 5295 & 1357 \\
\hline O1 & Ton & 260 & 3416532 & 3028 & 1023276.31 & 443252.68 \\
\hline O2 & Ton & 260 & 1048059 & 25437 & 535190.25 & 204366.56 \\
\hline O3 & Ton & 260 & 9081789 & 690406 & 5272682.78 & 1253762.45 \\
\hline O4 & $\%$ & 260 & 100 & 60 & 68.37 & 11.62 \\
\hline O5 & $\%$ & 260 & 98 & 54 & 62.56 & 18.38 \\
\hline
\end{tabular}

Data resources from China City Statistical Yearbook (2008-2017), China Environmental Statistics Yearbook(2008-2017), Zhejiang Natural Resources and Environment Statistical Yearbook(2008-2017), Anhui Statistical Yearbook(2008-2017) and the 26 cities statistical yearbooks of the Yangtze River Delta urban agglomeration.

\section{EMPIRICAL RESULTS}

\subsection{SUPER-SBM DEA model is used to calculate the initial efficiency value}

When using the DEA model to evaluate the efficiency of DMU, the number of DMU needs to be greater than twice the sum of input and output indicators and the value of each indicator cannot be negative. The sample selected in this paper is 26 cities in the Yangtze River Delta urban agglomeration, and the number of input and output indicators is 8 , which meets the requirements of the DEA model. The input and output indicators of the DMU are all positive values, and the corresponding output indicators are also expected outputs, and no adjustments are needed. According to the input indicators and output indicators of 26 cities in 2008-2017, we use the SUPER-SBM EA model and selected MAXDEA 5.2 software to calculate the comprehensive efficiency value, pure technical efficiency value and scale efficiency value of environmental pollution control investment in each city. The specific results are shown in the figure 1 . It can be seen from Figure 1 that the average initial investment efficiency of environmental pollution control of the Yangtze River Delta in China from 2008 to 2017 is less
According to the "Development Plan of the Yangtze River Delta Urban Agglomeration”, the Yangtze River Delta urban agglomeration consists of 26 cities. In order to evaluate the relative trend of the investment efficiency of urban agglomeration environmental pollution control, the sample period of the corresponding indicator data is 2008-2017. The missing part of the data is supplemented by the mean method of the data of the adjacent year. In addition, in order to eliminate the impact of inflation factors on the related variables, variables related to inflation in this paper are deflated based on 2008. Descriptive statistics for all input and output indicators are shown in Table 2. 


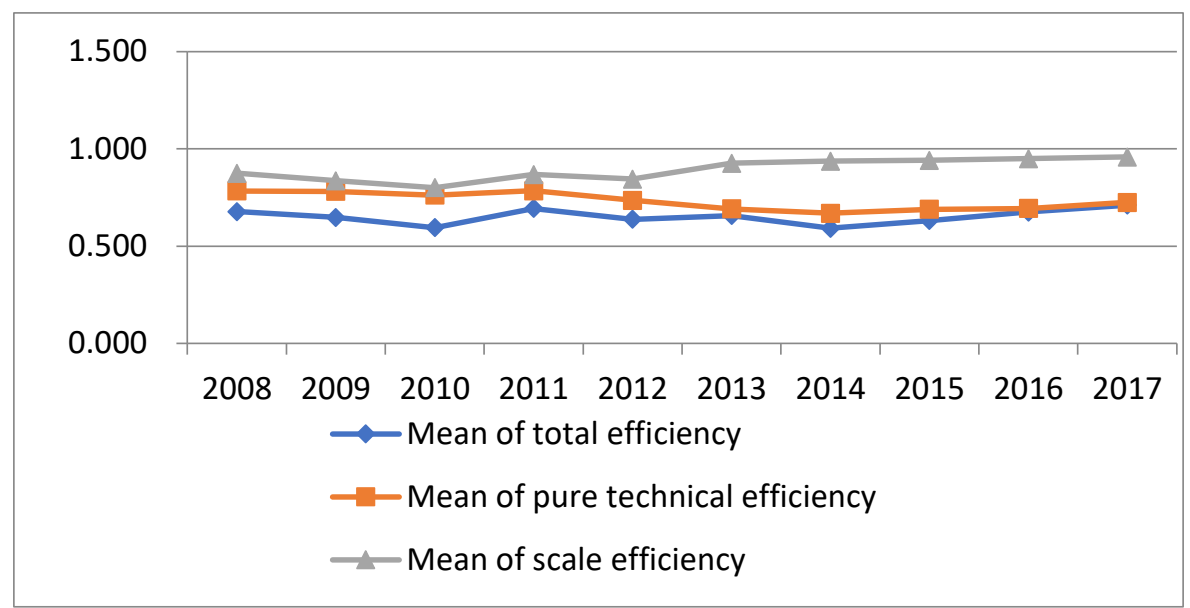

Figure 1. Initial efficiency of environmental pollution investment in the Yangtze River Delta urban agglomeration, China, 2008-2017

\subsection{The impact direction of external environmental variables on investment efficiency of environmental pollution control can be determine by using Tobit regression}

According to the environmental Kuznets curve (EKC) theory, environmental effects can be decomposed into scale effects, structural effects and technical effects. The factors affecting the investment efficiency of environmental pollution control can be attributed to economic operation factors, institutional change factors and regional characteristics(Wang, Shen and Zhou,2017)[29]. Considering the integrity and availability of data, this paper chooses the per capita GDP
(GDP) and contribution of secondary industry to GDP (SED) to represent economic operational factors, the ratio of FDI to GDP (FDI) and the levy on sewage charge (GOV) to represent the institutional change factors, the year-end proportion of urban population to total population $(\mathrm{CZ})$ to represent the regional characteristics. The panel Tobit model is used to analyze the environmental pollution investment efficiency (IE) of the Yangtze River Delta urban agglomeration, and the influential direction of external environmental variables on the efficiency investment of environmental pollution is determined. The source of the above external environmental variables is the same as the source of environmental pollution control input and output indicators.

Table 3. Tobit model regression result

\begin{tabular}{l|l|l|l|l}
\hline Variable & Coefficient & Std.Error & z-Statistic & Prob. \\
\hline C & $1.3075^{\star * *}$ & 0.1244 & 8.2635 & 0.0000 \\
\hline GDP & $0.0649^{\star *}$ & 0.3651 & 2.8740 & 0.0245 \\
\hline SED & $-0.0836^{\star * *}$ & 0.2876 & -2.1218 & 0.0026 \\
\hline FDI & $-0.0057^{*}$ & 0.3495 & -1.8687 & 0.0645 \\
\hline GOV & $0.0251^{\star *}$ & 0.2462 & 1.5286 & 0.0391 \\
\hline CZ & $-0.2162^{\star *}$ & 0.1488 & -3.5486 & 0.0147 \\
\hline
\end{tabular}

Note: $* * *$ means bilateral significant correlation at $1 \%$ level, $* *$ means bilateral significant correlation at 5\% level and $*$ means bilateral significant correlation at $10 \%$ level.

It can be seen from Table 3 that the regression coefficients of environmental variables GDP and GOV are positive and statistically significant, which indicates that increasing the external environmental variables is not conducive to increasing the efficiency of investment in environmental pollution control in the Yangtze River Delta urban agglomeration. They are classified as input indicators according to the principle of homogeneity, called negative environmental variables. The regression coefficients of the environmental variables SED, FDI and
CZ are negative and statistically significant, and are classified into output indicators according to the principle of isotropicity, called positive environmental variables. The above external environmental factors interfere with the real situation, so the SFA method can be used to correct the impact of the above environmental factors and random factors on the investment efficiency evaluation of environmental pollution control in the Yangtze River Delta urban agglomeration. 


\subsection{The impact of environmental factors and random interference factors on investment efficiency can be corrected by using SFA}

According to the Tobit model regression results, the frontier cost equation in the SFA method is used to construct an analysis framework that takes the input slack variables as the dependent variable, the negative environmental variables GDP and GOV as the independent variable and includes the random errors and management inefficiency, and an analytical framework that takes the output slack variables as the dependent variable, the positive environmental variables SED, FDI and $\mathrm{CZ}$ as the independent variables, and includes random errors and management inefficiencies. Regression was performed by Frontier 4.1 software, and the results were shown in table 4 and table 5 .

Table 4. SFA regression results of input slack variables on environmental variables

\begin{tabular}{c|c|c|c}
\hline dependent variables & $\begin{array}{c}11 \\
\text { slack variables }\end{array}$ & $\begin{array}{c}12 \\
\text { slack variables }\end{array}$ & $\begin{array}{c}13 \\
\text { slack } \\
\text { variables }\end{array}$ \\
\hline independent variables & $-0.0453^{\star \star \star}$ & $0.0011^{\star \star \star}$ & $-0.4180^{\star \star \star}$ \\
\hline constant term & $-0.0531^{\star \star}$ & $-0.0436^{\star \star}$ & $-0.0714^{\star \star}$ \\
\hline GDP & $-0.0238^{\star \star}$ & $-0.0150^{\star \star}$ & $-0.0509^{\star \star \star}$ \\
\hline GOV & $0.0099^{\star \star \star}$ & $0.0023^{\star \star *}$ & $0.0485^{\star \star *}$ \\
\hline sigma-squared & $0.9531^{\star \star}$ & $0.9500^{\star \star}$ & $0.9999^{\star \star *}$ \\
\hline gamma & -170.8158 & -147.1643 & -139.75 \\
\hline Log likelihood function & 19.3952 & 16.8948 & 36.7189 \\
\hline
\end{tabular}

Note: *** means bilateral significant correlation at $1 \%$ level, ** means bilateral significant correlation at $5 \%$ level and * means bilateral significant correlation at $10 \%$ level.

Table 5. SFA regression results of output relaxation variables on environmental variables

\begin{tabular}{|c|c|c|c|c|c|}
\hline Dependent variables & $\begin{array}{c}01 \\
\text { slack variables }\end{array}$ & $\begin{array}{c}\mathrm{O} 2 \\
\text { slack variables }\end{array}$ & $\begin{array}{c}\mathrm{O} 3 \\
\text { slack variables }\end{array}$ & $\begin{array}{c}\text { O4 } \\
\text { slack variables }\end{array}$ & $\begin{array}{c}\text { O5 } \\
\text { slack variables }\end{array}$ \\
\hline constant term & $-0.0339^{* * *}$ & $0.0241^{\star \star \star}$ & $-0.0213^{\star \star \star}$ & $0.0561^{\star \star \star}$ & $0.0464^{\star * *}$ \\
\hline SED & $0.2361^{\star \star}$ & $0.2595^{*}$ & $0.1922^{\star}$ & $0.1248^{* \star}$ & $0.1367^{* *}$ \\
\hline FDI & $0.0519^{\star \star}$ & $0.0119^{\star \star}$ & $0.0255^{\star}$ & $0.0146^{*}$ & $0.0132^{*}$ \\
\hline $\mathrm{CZ}$ & $0.0436^{\star \star}$ & $0.0216^{\star \star}$ & $0.0347^{\star \star \star}$ & $0.0721^{\star \star \star}$ & $0.0987^{\star \star \star}$ \\
\hline sigma-squared & $0.0596^{\star \star \star}$ & $0.0798^{\star \star \star}$ & $0.0269^{\star \star \star}$ & $0.0573^{\star \star \star}$ & $0.0436^{\star \star \star}$ \\
\hline gamma & $0.9976^{\star \star}$ & $0.9999 * \star$ & $0.9917^{\star \star}$ & $0.9983^{\star \star}$ & $0.9864^{\star \star}$ \\
\hline log likelihood function & -121.8799 & -127.3644 & -122.6452 & -119.5521 & -108.6573 \\
\hline LR test of the one-sided error & 15.1303 & 16.4791 & 15.9849 & 13.7682 & 14.7954 \\
\hline
\end{tabular}

Note: *** means bilateral significant correlation at $1 \%$ level, $* *$ means bilateral significant correlation at $5 \%$ level and $*$ means bilateral significan correlation at $10 \%$ level.

It can be seen from Table 4 that both GDP and GOV indicate that there is a significant relationship between the input slack variable and the environmental variable through the significance test. According to the independent variable coefficient of the SFA regression result, it is concluded that GDP and GOV are negatively correlated with the slack variables of input indicators I1, $\mathrm{I} 2$, and I3, which means increasing GS and SF can decrease the redundant value of the input indicator and increase the investment efficiency of environmental pollution control. It shows that the improvement of urban economic development level can make the city have more funds to invest in research and development of pollution control technology and products, which has scale economies effect. At the same time, the high amount of urban government sewage charges can urge enterprises to adopt energy - saving and environmental friendly production methods, or improve their internal management level, and ultimately promote the efficiency of investment in environmental pollution control. 
It can be seen from Table 5 that SED, FDI and CZ all show a significant relationship between the output slack variable and the environmental variable through the significance test. According to the independent variable coefficient of the SFA regression result, it is concluded that increasing SED, FDI and $\mathrm{CZ}$ will boost the insufficient value of $\mathrm{O} 1, \mathrm{O} 2, \mathrm{O} 3, \mathrm{O} 4$ and $\mathrm{O} 5$ output indicators, and reduce the investment efficiency of environmental pollution control. It shows that the rapid development of urban industry will have an adverse impact on environmental pollution control, because industrial pollution is the main pollutant in economic activities, and the over-exploitation of natural resources and the excessive discharge of industrial waste will greatly reduce the investment efficiency of environmental pollution control. The improvement of openness to the outside world can help cities to introduce advanced environmental pollution control technologies and management methods. It may become a refuge for foreign polluting enterprises at the same time, leading to worse environmental pollution. The improvement of urbanization level is often accompanied by industrial prosperity, and the increase of enterprises and population increases the emission of pollutants and raises the pressure on environmental protection and governance, but it also brings opportunities for environmental governance. From the results of this study, the degree of openness and the level of urbanization have a negative effect on the investment efficiency of environmental pollution control than the positive effect.

\subsection{The adjustment efficiency value is calculated by adjusting the input-output indicator value and using Super-SBM DEA model}

Using the adjusted input and output indicator value, the Super-SBM DEA model is selected to calculate the comprehensive efficiency value, pure technical efficiency value and scale efficiency value of environmental pollution control investment in 26 cities in the 2008-2017 Yangtze River Delta. Therefore, the efficiency level obtained by the advantages and disadvantages of the external environment is eliminated, and all DMUs are adjusted to the same environmental platform to obtain the pure management efficiency of the environmental pollution control investment of each city, as shown in Figure 2. According to Figure 2, after removing the influence of environmental factors, random errors and management inefficiency, the comprehensive efficiency, the average pure technical efficiency and scale efficiency of the investment adjustment of the environmental pollution control of the Yangtze River Delta in China in 2008-2017 have declined. The average overall efficiency is mainly around 0.54 , which means that under the condition of maintaining the same output, the pure management efficiency of the investment in environmental pollution control of the Yangtze River Delta urban agglomeration has about $46 \%$ of input waste. Compared with the mean technical efficiency and scale efficiency before adjustment, the adjusted pure technical efficiency average decreased by 0.07 to 0.662 , and the adjusted scale efficiency average decreased by 0.139 to 0.755 , It shows that the scale efficiency is more affected by exogenous environmental and random factors than pure technical efficiency, and the investment efficiency of environmental pollution control in the Yangtze River Delta urban agglomeration urgently needs to be effectively improved.

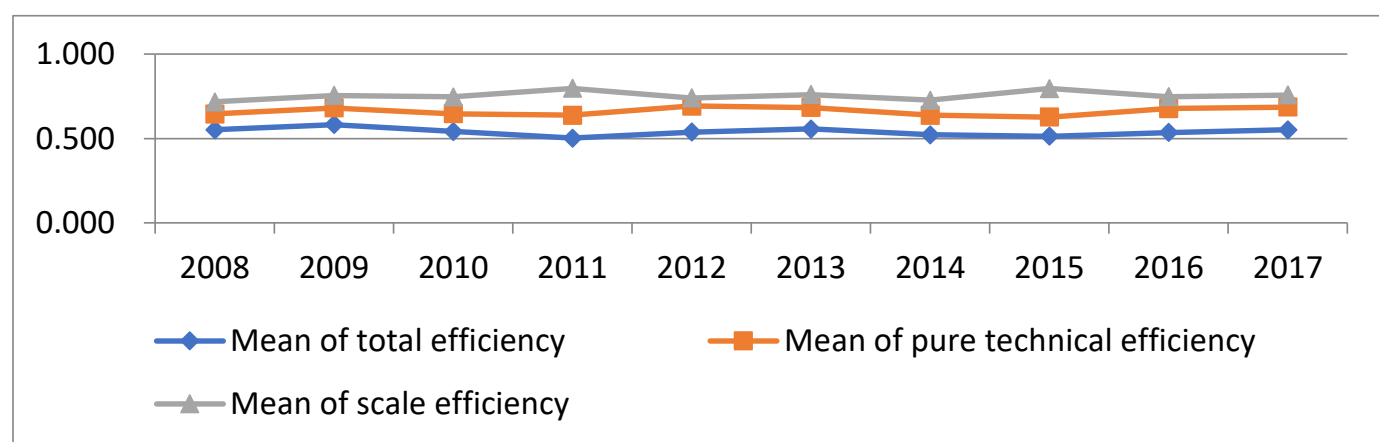

Figure 2. Adjust efficiency of environmental pollution investment in the Yangtze River Delta urban agglomeration, China, 2008-2010

According to the above calculation results, it can be seen that from 2008 to 2017 , the pure management efficiency of environmental pollution treatment investment in China's Yangtze river delta urban agglomeration is generally poor and shows a small range of change, and there is a large degree of input waste. The scale efficiency is relatively higher than the pure technical efficiency, but it is greatly affected by exogenous environmental factors and random impact factors. At the same time, the exogenous environmental factors that affect the input slack variables of environmental pollution control in the Yangtze river delta urban agglomeration and further affect the governance efficiency mainly include the urban per capita GDP and the government levy on sewage charges, which have positive effect on the investment in environmental pollution control. The exogenous environmental factors affect output slack variables of environmental pollution 
control in the Yangtze river delta urban agglomeration and further affect the efficiency of environmental pollution control mainly include the scale of the secondary industry, FDI and urbanization level, which have negative effects on the environmental pollution control investment.

\section{CONCLUSIONS}

In order to effectively improve the investment efficiency of environmental pollution control in the Yangtze River Delta urban agglomeration and strengthen the environmental protection of urban agglomerations, the following conclusions and research reference can be determined

Implement the industrial structure optimization strategy and adhere to the economic sustainable development strategy. Industrial production is the main source of pollutants in the Yangtze River Delta urban agglomeration. We can promote the transformation and upgrading of traditional industrial economy by cultivating and expanding the economic growth points of emerging industries and promoting the tertiary industry to become the pillar of economic development in the Yangtze River Delta region.

(2) Improve the quality of foreign capital the government regulatory system. Under the background of building an environment-friendly environment, local governments of the Yangtze River Delta urban agglomeration should formulate a sustainable investment strategy that is consistent with environmental development. In the process of attracting investment, we should increase environmental regulation and pay attention to the combination of economic benefits, environmental benefits and resource benefits.

(3) Improve the regional pollution prevention and control linkage and cooperation mechanism, and implement more active environmental and economic policies. Taking the air and water environmental pollution that is currently the most concerned as an entry point, improve the regional pollution prevention and control linkage mechanism to reduce chemical pollution and total coal consumption.

(4) Optimize urban planning and implement new urbanization development. In theory, urbanization is a “double-edged sword" for environmental pollution control. In the process of urbanization, the local governments of the Yangtze River Delta urban agglomeration fail to make an overall plan for urbanization and environmental pollution control. As a result, the improvement of urbanization level had a negative impact on the investment efficiency of environmental pollution. We should strengthen and optimize urban planning, adhere to the new urbanization path which is intensive, low-carbon, green and intelligent.

\section{Funding}

This work has received funding from the Major project of national social science foundation of China (15BGL056). Fund project for the forward-looking development strategy research of the basic scientific research operating expenses of central universities (NW2019002), Fund Projects from Philosophy and Social Science Fund of Universities in Jiangsu Province (2017SJB2058), Introducing Talent Research Fund Project from Nanjing Institute of Technology (YKJ201832). We would also like to thank the environmental protection department of Jiangsu and Zhejiang and Anhui for providing the research data.

\section{Conflict of Interest}

The authors declare no conflict of interest.

\section{REFERENCES}

[1] Freeman A M and Haveman R H.(1973) The Economics of Environmental Policy.-Land Economics47(3):18-30.

[2] Watanabe M and Tanaka K. (2007) Efficiency analysis of Chinese industry: A directional distance function approach. -Energy Policy 35(12):63236331.

[3] Larsson J and Telle K.(2008) Consequences of the IPPC' s BAT Requirements for Emissions and Abatement Costs: A DEA Analysis on Norwegian Data.- Environmental \& Resource Economics 41(4):563-578.

[4] Chen H W, Chang N,B and Chen J C.(2010) Environmental Performance Evaluation of Largescale Municipal Solid Waste Incinerators using Data Envelopment Analysis.-Waste Management 30(7):13-23.

[5] Hua Z, Bian Y and Liang L.(2007) Eco-efficiency analysis of paper mills along the Huai River: An extended DEA approach.-Omega 35(5):578-587.

[6] Mandal S K and Madheswaran S . (2010) Causality between energy consumption and output growth in the Indian cement industry: An application of the panel vector error correction model (VECM). Energy Policy 38(11):6560-6565.

[7] Suzuki S, Nijkamp P and Rietveld P. (2015) A target-oriented data envelopment analysis for energy-environment efficiency improvement in Japan.- Energy Efficiency 8(3):433-446.

[8] Yang Jun and Lu Yujia. (2012) Efficiency of China's environmental governance input based on 
three-stage DEA. -Journal of Systems Engineering 27(5):699-711.

[9] Guo Sidai,Tong Meng and Zhang Hua.(2018) Analysis of Investment Efficiency and Its Influencing Factors of Environmental Governance in China.Statistics and Decision (8):113-117.

[10] Sun J, Wang Z and Li G. (2018) Measuring emission-reduction and energy-conservation efficiency of Chinese cities considering management and technology heterogeneity. Journal of Cleaner Production 175:561-571.

[11] Li Hongwei,Ren Yingying and Tao Min.(2019) Evaluation of China's Environmental Governance Investment Efficiency and Its Convergence Analysis.-Ecological Economy 35(04):179-184.

[12] Mardani A, Zavadskas E K and Streimikiene D. (2016) A comprehensive review of data envelopment analysis (DEA) approach in energy efficiency.- Renewable and Sustainable Energy Reviews 70:1298-1322.

[13] Charnes A.,Coopers W.W. and Rhodes.(1978) Measuring the Efficiency of Decision Making Units.-European Journal of Operational Research 2(6):429-444.

[14] Banker R D and Morey R C. (1986) Efficiency Analysis for Exogenously Fixed Inputs and Outputs.-Operations Research 34(4):513-521.

[15] Coelli T.(1998) A Multi-stage Methodology for the Solution of Orientated DEA Models.- Operation Research Letters 23(3):143-149.

[16] Fried H O, Schmidt S S, Yaisawarng S. (1999) Incorporating the Operating Environment into a Nonparametric Measure of Measure of Technical Efficiency.-Journal of Productivity Analysis 12(3):249-267.

[17] Fried H O, Lovell C A K and Schmidt S S, et al.(2002) Accounting for Environmental Effects and Statistical Noise in Date Envelopment Analysis.-Journal of Productivity Analysis 17(1/2):157-174.

[18] Qiong W and Cheng-Xuan G.(2017) Research on Financing Efficiencies of Strategic Emerging Listed Companies by Six-Stage DEA Model.Mathematical Problems in Engineering 2017:1-8.

[19] Sun J, Yuan Y and Yang R.(2017) Performance evaluation of Chinese port enterprises under significant environmental concerns: An extended DEA-based analysis.-Transport Policy (60):75-86.

[20] Wang Q, Hang Y and Hu J L.(2018) An alternative metafrontier framework for measuring the heterogeneity of technology.-Naval Research Logistics 65(5):427-445.

[21] Sun J,Li G and Wang Z.(2019) Technology heterogeneity and efficiency of China's circular economic systems: A game meta-frontier DEA approach. Resources.- Conservation and Recycling (146):337-347.

[22] Tone K.(2002) A Slacks-Based Measure of Superefficiency in Data Envelopment Analysis.European Journal of Operational Research 143(1):32-41.

[23] Tone K.(2001) A Slacks-Based Measure of Efficiency in Data Envelopment Analysis.European Journal of Operational Research 130(3):498-509.

[24] Tobin J.(1958) Estimation of Relationships for Limited Dependent Variables.-Econometrica: Journal of the Econometric Society 26(1):24-36.

[25] Aigner,Lovell and Schmidt.(1977) Formulation and Estimation of Stochastic Frontier Production Functions Models. -Journal of Econometrics (6):2137.

[26] W ang Na, Shen Junya and Zhou Tianle.(2017) Research on Green Investment Efficiency Based on Three-stage DEA Method.-The Theory and Practice of Finance and Economics 38(2):42-47. 